\title{
(DES)CIVILIZAÇÃO E BARBÁRIE NA GUERRA COLONIAL EM MOÇAMBIQUE: UMA ANÁLISE DO PERSONAGEM LUÍS ALEX DE A COSTA DOS MURMÚRIOS DE LÍDIA JORGE
}

\author{
DECIVILIZATIONAND BARBARISM IN THE COLONIAL WAR IN \\ MOZAMBIQUE: AN ANALYSIS OF THE CHARACTER LUIS ALEX OF \\ A COSTA DOS MURMÚRIOS BY LÍDIA JORGE
}

Adriano Carlos Moura'

Ana Beatriz Rodrigues Gonçalves²

\begin{abstract}
RESUMO: Estudo de caso é um método comumente empregado em pesquisas com objetos do mundo concreto, indivíduos ou pequenos grupos sociais. Este trabalho propóe tal emprego para análise de um sujeito do universo ficcional: o personagem Luís Alex do romance A costa dos murmúrios (2004) da romancista portuguesa Lídia Jorge. Pretende-se compreender o processo que fez com que o estudante de matemática, noivo apaixonado pela protagonista e narradora Evita/Eva Lopo se transformasse a seus olhos num soldado capaz de degolar pessoas, fincar suas cabeças em paus exibindo-as como troféus durante a guerra colonial em Moçambique. Inicialmente o personagem será estudado sob a perspectiva de Aimé Cesaire de que a colonizaçăo em vez de cumprir sua missâo civilizadora transformou o colonizador em bárbaro. Buscar-se-á, pelas mudanças ocorridas com o personagem no decorrer da narrativa, quais fatores contribuíram para tal inversâo e em que momento da vida dele isso ocorreu. A hipótese levantada, sustentada pelo conceito de devir em Gilles Deleuze e Félix Guattari, é de que o personagem, como qualquer ser humano, guarda em si devires animal, fera, máquina de guerra, além de possibilidades identitárias que podem escapar ao domínio consciente e racional.
\end{abstract}

Palavras-chave: A costa dos murmúrios; devir; literatura portuguesa; Lídia Jorge.

ABSTRACT: Case study is a method commonly employed in research with concrete world objects, individuals or small social groups. This paper proposes such employment for the analysis of a subject of the fictional universe: the character Luís Alex of the novel A costa dos murmúrios (2004) by the Portuguese novelist Lídia Jorge. It is intended to understand the process by which the math student, fiancé in love with the protagonist and narrator Evita / Eva Lopo became a soldier capable of beheading people, putting their heads on clubs and display them as trophies during the war colonial times in

\footnotetext{
1 Professor de Literatura do curso de Letras do IF Fluminense e doutorando em Estudos Literários (UFJF). E-mail: adriano.moura@iff.edu.br

2 Professora associada II da Universidade Federal de Juiz de Fora e doutora em Letras pela University of Texas System.E-mail: acmoura36@yahoo.com.br
} 
Mozambique. Initially, the character will be studied from Aimé Cesaire's perspective that colonization instead of fulfilling its civilizing mission transformed the colonizer into a barbarian. We will seek, by the changes that have happened with the character in the course of the narrative, what factors contributed to that inversion and in what moment of his life. The hypothesis raised, supported by the concept of becoming in Gilles Deleuze and Félix Guattari, is that the character, like any human being, keeps in itself an animal, a beast, a war machine, as well as identity possibilities that can escape the conscious and rational domains.

Keywords: A costa dos murmúrios; devir; portuguese literature; Lídia Jorge.

\section{INTRODUÇÃO}

Aimé Cesaire inicia o seu Discurso sobre o colonialismo (1978) declarando que a Europa é indefensável. O autor martinicano critica, em seu texto, as açôes colonizadoras dos países europeus no continente africano pautadas por violência, assassinatos, genocídios, exploraçâo e escravidăo. A missâo civilizadora em relaçăo aos povos considerados bárbaros/selvagens da África fracassa duplamente. Primeiro por ter ficado claro que a cristianizaçáo e civilidade serviram apenas de álibi para que se perpetrasse a escravizaçáo dos negros e a exploraçáo das riquezas do continente. Segundo porque a experiência colonial "descivilizou" o europeu, visto que este assumiu práticas consideradas bárbaras e selvagens as quais deveria combater.

No romance A costa dos murmúrios (2014), de Lídia Jorge, o conflito entre soldados e oficiais portugueses e o movimento anticolonial em Moçambique é narrado sob a perspectiva de Evita/Eva Lopo, um duplo de personagem, autor ficcional / narrador. A obra é introduzida por um conto, "Os gafanhotos", cuja trama se concentra na festa de casamento de Evita e Luís Alex, ex-estudante de matemática servindo como alferes na guerra. Os soldados e oficias săo surpreendidos pela notícia da morte de negros por envenenamento por álcool metílico, e cujos cadáveres săo transportados por caminhóes de lixo. O cenário é o Hotel Stella Maris, assolado por uma tempestade de gafanhotos, às vésperas de uma importante operaçăo de guerra. 0 romance propriamente dito inicia-se depois do término do conto. Eva Lopo resolve recontar o episódio vinte anos depois do ocorrido, revezando-se ora como a personagem Evita do conto, ora como narradora, a representaçấo da ambivalência de uma mesma personagem.

Năo se pretende, porém, analisar o romance a partir da protagonista, tampouco a narrativa em si, mas tecer algumas consideraçôes acerca do que se conceituará como devir-identitário, tendo o personagem Luís Alex, o noivo, como objeto de estudo, adaptando o método de estudo de caso a um sujeito ficcional, năo a um ser humano real como comumente se faz, o que caracteriza o experimentalismo deste trabalho. Considerando a obra com características de romance histórico, a verossimilhança entre a figura ficcional e a possibilidade de existência de um sujeito real, cujas práticas de guerra sejam comuns, é possível reforçar o uso experimental da proposta metodológica. O conceito de devir será utilizado tendo como base teórica as conceituaçōes de Gilles Deleuze, Félix Guattari e Achile Mbembe, suas conclusôes acerca do devir-negro do mundo e de necropolítica.

Buscar-se-á, por meio da análise da transiçăo por que passa o alferes, confirmar a hipótese de que ele é reflexo do "asselvajamento" e da descivilizaçáo do colonizador, 
como resultado da experiência colonial. Para tal, serâo convocadas também para o estudo as reflexôes de Aimé Cesaire sobre as relaçôes do europeu e os povos submetidos à colonizaçāo.

\section{DA IDENTIDADE HÍBRIDA AO DEVIR IDENTITÁRIO}

O hibridismo é uma marca da experiência colonial. Impossível pensar as identidades tanto do colonizador quanto do colonizado como instâncias incólumes às influências que um exerceu sobre o outro. No que concerne ao plano linguístico, os africanos assimilaram mais da língua do europeu do que este daquele em virtude de as línguas nativas serem consideradas "menores", além da multiplicidade linguística que compunha e compóe os países africanos. Arcaico e moderno, rural e urbano, popular e erudito, centro e periferia; săo muitas as perspectivas por meio das quais se pode pensar o conceito de hibridismo, sobretudo se for considerado o estudo de Néstor Garcia Canclini, (2015) sobre o tema.

A obra de Canclini năo se debruça essencialmente sobre o continente africano e suas ex-colônias, mas sobre a realidade da América Latina. Apesar disso, é possível perceber alguns pontos comuns acerca da experiência em relaçáo ao que se convencionou chamar de modernidade ou culturas híbridas. Para o autor, na América Latina, as tradiçóes ainda permanecem e o que os países considerados desenvolvidos chamaram de modernidade ainda náo havia chegado.

Dentre as hipóteses de Canclini, pode-se citar a de que

a incerteza em relaçáo ao sentido e ao valor da modernidade deriva năo apenas do que separa naçóes, etnias e classes, mas também dos cruzamentos socioculturais em que o tradicional e o moderno se misturam (CANCLINI, 2015, p.18).

Sobre a modernidade latino-americana, escreve:

Fomos colonizados pelas naçôes europeias mais atrasadas, submetidas à ContraReforma e a outros movimentos antimodernos, apenas com a independência pudemos iniciar a atualizaçăo de nossos países. Desde entăo, houve ondas de modernizaçăo. (CANCLINI, 2015, p.67).

Moçambique, no romance de Lídia Jorge, é um país apartado de qualquer experiência europeia de modernidade. Diferente das naçóes da América colonizadas pelos espanhóis, o país africano só alcançou sua independência em 1975, sendo a narrativa de A costa dos murmúrios ambientada no final da luta pela independência. Portugal era, entăo, corroborando o pensamento de Canclini, uma das naçóes mais atrasadas da Europa, como era também a Espanha.

Boaventura Sousa Santos (2013) desenvolve a tese de Portugal como um país paradoxal. Mesmo sendo europeu e tido como povo "aberto" e "afável", Portugal é considerado pelo sociólogo uma naçáo relativamente desconhecida, estranha às demais naçóes da Europa. Aponta como uma das razóes o isolamento causado pelos quarenta e um anos de ditadura do Estado Novo. Era centro em relaçăo às colônias, mas periferia perante outros países, como Inglaterra e França. 
Ser português é uma interpelaçăo constante na história do povo luso desde que o mito camoniano passou a ser contestado. Retomando o objetivo do artigo, năo se discorrerá sobre a identidade portuguesa em termos de construçâo coletiva, mas de um sujeito específico, personagem romanesco, expressâo literária de uma série de devires possíveis.

Para Deleuze e Guattari, devir năo significa correspondência, analogia, tampouco imitaçáo. Os devires também nâo seriam mera imaginaçâo. "Os devires animais nâo sâo sonhos nem fantasmas. Eles sâo perfeitamente reais" (1997, p.18). Isso nâo significa que o homem se tornaria verdadeiramente um animal e animal outra coisa senâo aquilo que é. Ocorre é que "O devir náo produz outra coisa senáo ele próprio" (1997, p. 19). Pensar a condiçăo do sujeito partindo dessa perspectiva significa a compreensăo da identidade como um construir-se contínuo, podendo emergir comportamentos por vezes imprevisíveis, paradoxais, estranhos ao próprio indivíduo ou ao que se concebe como humano civilizado. Năo implica afirmar, porém, que năo haja no ser humano características que lhe possam ser cristalizadas, mas que o sujeito abriga uma série de identidades e comportamentos possíveis de serem desencadeados. Identidade, portanto, năo seria aquilo que fui, ou sou, tampouco o que virei a ser, mas o que pude ter sido, posso e poderei ser. A identidade abarcaria aspectos năo apenas culturais, mas também políticos, biológicos, estéticos, éticos, físicos, psíquicos, ou seja, tudo que de uma maneira ou outra afetaria a noçâo que o sujeito constitui acerca de si mesmo e do outro.

Os dois filósofos afirmam que, em termos de devir, nada é produzido por filiaçăo ou evoluçấo, mas por aliança de seres de origens completamente distintas de forma comunicativa e contagiosa como a simbiose. (DELEUZE; GUATTARI, 1997, p.19).

Em A costa dos murmúrios, Evita percebe em seu noivo uma obsessăo em se parecer com Forza Leal, seu superior na companhia de guerra a qual pertence. Na análise da personagem, é por imitaçâo que Luís Alex busca tal semelhança.

Contente, pede-me que me imagine alferes, que me imagine soldado, combatente, que me imagine às ordens do capităo. É difícil imaginar. Mas ele pede, tem o cabelo molhado, colado à cabeça, e as pastilhas espetam muito, póem-lhe as maçăs do rosto salientes como peras. Nâo é mais a pessoa com quem fiz namoro, a primeira pessoa com quem me deitei na carruagem do comboio, atravessando uma planície com lua (JORGE, 2004, p.71).

É importante destacar que tanto Evita quanto Luís Alex sâo personagens construídos por Eva Lopo, que também é um personagem, porém nascida da mente criadora de Lídia Jorge. Para evitar ambiguidades, as referências à personagem/narradora passarâo a ocorrer sob o signo Eva Lopo/Evita. O noivo, diegeticamente, é um personagem de profundidade psicológica extrema, no plano da realidade vivida por Evita também. Advém daí a dificuldade de ela perceber sua unidade e coerência, talvez porque ele năo as tenha. Em A personagem da ficçâo (2014), no capítulo em que se aborda especificamente a personagem romanesca, o crítico Antonio Cândido conclui que a noçấo que temos acerca de um outro ser é sempre incompleta e fragmentária. Eva Lopo/Evita podia descrever fisicamente o noivo, porém ao que havia para além da superfície seu acesso era apenas parcial. Os diferentes Luís Alex contidos no noivo lhe văo sendo apresentados ao longo da narrativa. Evita e Luís tinham avistado Helena e 
Forza Leal pela beira do mar. Essa visăo provoca o pedido que Evita se sente incapaz de atender. É o momento em que percebe que nâo se tratava mais do homem por quem se apaixonara: o jovem estudante de matemática.

"Mas se nâo me escapasse e se soubesse, năo seria para dizer a Helena de Tróia a quem me une apenas um homem por ser a imitaçâo de outro homem" (JORGE, 2004, p.109). Evita vê o noivo como uma imitaçăo caricaturesca de Forza Leal. Porém, esta análise pretende interpretar as açóes desse personagem năo apenas pela perspectiva mimética. Cândido destaca o fato de os personagens ficcionais estarem relacionados com figuras reais, sem as serem, entretanto a verossimilhança torna possível a existência real do ser fictício. Por mais que nâo seja um personagem da história real de Moçambique, a existência de soldados como Luís Alex é totalmente possível no contexto de uma guerra como foi a colonial.

Segundo Cândido,

o romance, ao abordar as personagens de modo fragmentário, nada mais faz do que retomar, no plano da técnica da caracterizaçầo, a maneira fragmentária, insatisfatória, incompleta, com que elaboramos o conhecimento dos nossos semelhantes" (CANDIDO, 2014, p.58).

Assim é o conhecimento de Eva Lopo/Evita acerca do noivo. O leitor de A costa dos murmúrios acompanha a personagem/narradora na descoberta das várias identidades do noivo, e compreende sua unidade, compreensăo que parece impossível à Evita, cujo acesso é apenas parcial e fragmentário. A ficçăo nos dá um conhecimento mais completo dos seres, diferente da imagem fragmentária que a vida real confere. Eis na trama de Lídia Jorge uma questăo paradoxal: Eva Lopo compreende a unidade do noivo cujas características físicas e psicológicas ela descreve, enquanto Evita é interpelada por dúvidas e surpresas acerca do homem com quem se casara. Só depois de sua morte, antecipada ao leitor no conto que introduz o romance, é que Eva se sente capaz de perceber, nâo mais de forma fragmentária, o noivo. Seguindo ainda as palavras de Cândido: "Poderíamos dizer que um homem só nos é conhecido quando morre" (CANDIDO, 2014, p. 58). Consoante seu pensamento, somente depois da morte se pode elaborar uma interpretaçấo completa dos seres, pois se estabelece um ponto definitivo. Ao romancista é dado o conhecimento pleno dos personagens que cria. Somente depois da morte os indivíduos deixam de produzir seus devires. Ou, seus devires já produzidos podem ser observados a partir de uma unidade espectral de figuras contrastantes habitantes de um mesmo corpo físico.

Sâo nos agenciamentos constituídos pelas multiplicidades de termos heterogêneos que os devires animais do homem operam. Segundo Deleuze e Guattari, esses devires-animais năo pertenceriam a agenciamentos como família e aparelhos de Estado, mesmo que neles surjam. Os autores se referem às sociedades secretas, de guerra, de crime.

A máquina de guerra é sempre exterior ao Estado, mesmo quando o Estado se serve dela, e dela se apropria. O homem de guerra tem todo um devir que implica multiplicidade, celeridade, ubiquidade, metamorfose, traiçăo, potência e afecto. Os homens-lobo, os homens-urso, os homens-fera, os homens de toda animalidade, confrarias secretas, animam os campos de batalha (DELEUZE; GUATTARI, p.24-25). 
Mais do que diferenciar espécies de animais, faz-se necessário estabelecer a distinçăo de seus diferentes modos e como săo integrados às instituiçóes sociais e aparelhos do Estado. Na guerra, o soldado é desprovido de toda sua humanidade, civilidade e racionalidade. Talvez, por isso emerja seu devir-fera, animal. Vive com os demais como matilhas ou alcateias, geralmente sob uma liderança, assim como ocorre aos câes e aos lobos. Luís Alex assume sua incapacidade para pensar racionalmente no campo de guerra. À ameaça da morte, năo há espaço para que se racionalizem as açôes, resta ao personagem a obediência às ordens ou o atendimento aos chamados do que lhe é mais instintivo, primitivo e também "selvagem".

Lídia Jorge constrói perante os olhos do leitor e de Evita os contrastes entre a civilizaçâo representada pelo noivo professor de matemática e a barbárie do soldado, como no excerto a seguir:

\begin{abstract}
Via-se nitidamente o pau, a cabeça espetada, mas o soldado que a agitava náo era um soldado, era o noivo. Helena de Tróia disse - 'Vê aqui o seu noivo?' Ela queria que Evita visse. Era claro como a manhă que despontava que Helena de Tróia me havia trazido até àquela divisăo da casa para que eu visse sobretudo o noivo (JORGE, 2004, p.145).
\end{abstract}

Helena exibe a Evita uma sequência de fotos contidas numa caixa. Em algumas dessas fotos o homem que outrora fora seu noivo está irreconhecível năo pela aparência, mas pelas açóes que executa. Helena năo lhe mostrou aquele material para que ela "visse" o noivo, mas para confrontá-la com o devir-fera-soldado do noivo. O homem que degolava cabeças já habitava o que investigava fórmulas matemáticas e com quem Evita se casara.

O noivo, Luís Alex, o alferes săo diferentes nomes utilizados pela narradora para se referir a um mesmo personagem. Nâo se trata, porém, de recurso meramente coesivo como substituiçăo por sinônimos, hiperônimos ou expressôes que serviriam para recuperar um termo sintático sem repeti-lo. Cada nome esconde um sujeito, um devir-homem, soldado, professor, ou apenas o noivo de uma portuguesa que só por meio da construçáo narrativa é capaz de desvendar as possibilidades identitárias do homem que pensou que um dia conhecesse. Mas o que poderia transformar um sonhador professor de matemática português recém-casado com a mulher que ama num soldado degolador de negros em Moçambique?

\title{
A GUERRA COLONIAL E O “ASSELVAJEMENTO” DO COLONIZADOR
}

Aimé Cesaire (1978) classifica como decadente, enferma e moribunda a civilizaçăo que năo consegue resolver os problemas suscitados por ela, que fecha os olhos para eles e trapaceia com seus princípios. Assim, declara a Europa como indefensável, entendendo a condiçấo colonial como um dos principais problemas gerados pelo Velho Mundo. A colonizaçấo estava longe do ideal de evangelizaçăo e propagaçăo do progresso civilizatório, estando o colonizador mais para pirata, seviciador, aventureiro, comerciante com sede de ouro e outras riquezas.

Só mesmo a hipocrisia e a desonestidade do colonizador permitem igualar cristianismo à civilizaçấo e paganismo à selvageria, para ratificar o racismo e a violência praticados contra "Índios, amarelos e negros" (CESAIRE, 1978, p. 15). 
A colonizaçáo descivilizou o colonizador, embrutecendo-o, degradando-o, despertando nele "instintos ocultos, para a cobiça, para a violência, para o ódio racial, para o relativismo moral, e mostrar que, sempre que há uma cabeça degolada e um olho esvaziado no Vietname e que em França se aceita (...)" (CESAIRE, 1978, p.17), há uma asselvajamento da Europa.

Compreendendo o personagem ficcional Luís Alex como espelhamento mimético de um real soldado a serviço da metrópole portuguesa em território africano, é possível considerá-lo exemplo do asselvajamento de que fala Cesaire no ensaio Discurso sobre o colonialismo

“O problema é que em tempos me apaixonei por um rapaz inquieto à procura duma harmonia matemática, e hoje estou esperando por um homem que degola gente e a espeta num pau" (JORGE, 2004, p. 182). O noivo transformara-se numa peça da máquina de guerra. Em Necropolítica (2018), Achille Mbembe afirma que na guerra das colônias o direito de matar năo está sujeito a nenhum tipo de regra institucional. "As guerras coloniais sấo concebidas como a expressâo de uma hostilidade absoluta que coloca o conquistador face a um inimigo absoluto". (MBEMBE, 2018, p. 37). Esse inimigo, porém, năo se trata de um sujeito oriundo do mundo dito "civilizado", năo era espanhol, francês, alemáo, italiano; mas de um outro totalmente desprovido de humanidade pela ideologia colonialista e ao mesmo tempo uma ameaça ao império e ao próprio colono. O negro africano havia se tornado, desde a política de implantaçăo da cultura de plantation, no sujeito cujo corpo se poderia violar, escravizar, matar, decapitar e exibir as partes como troféu. O devir-animal, o devir-objeto, inumano do corpo negro concedia ao europeu o "direito" de dele se apropriar.

O homem por quem Evita se apaixonara era o mesmo que exibia a cabeça de um negro numa estaca? Talvez. Em outra passagem do romance, ela procura respostas para o entendimento do que teria efetuado transformaçăo tâo radical na personalidade do noivo.

"Mas quando se tinha dado a mudança de Luís Alex? No momento em que reprovou em Astronomia? No momento em que soube da morte do campeáo de vela? No momento em que entrou no quartel pela porta guardada pelo soldado de chapéu de ferro?" (JORGE, 2004, p.153). Para a narradora, a força que impelia o noivo à pesquisa da Matemática era a mesma que fazia dele um degolador de negros em Moçambique. Segundo ela, "Entre o bem e o mal uma mortalha de papel de seda" (JORGE, 2004, p. 154). Comparando com a experiência nazista, afirma ainda que "Os carrascos de Auschwitz poderiam ter estado perto duma importante descoberta no domínio da Bioquímica" (JORGE, 2004, p.154).

Hitler era um homem dedicado à pintura. Luís Alex, à matemática. Para Cesaire, o que fez o líder nazista entrar para história como assassino, genocida, foi o fato de ter imposto a povos brancos da Europa práticas de extermínio e tortura até entăo só aplicáveis às colônias. $\mathrm{O}$ crime de Hitler năo foi violar os direitos de seres humanos, mas os de humanos brancos. Considerando a experiência argelina, Cesaire conclui que a colonizaçáo, violenta como foi imposta, é capaz de desumanizar o homem mais civilizado, se

fundada sobre o desprezo pelo homem indígena e justificada por esse desprezo, tende, inevitavelmente, a modificar quem a empreende, que o colonizador, para se dar boa consciência se habitua a ver no outro o animal, se exercita em tratá-lo como 
animal, tende, objetivamente, a transformar-se ele próprio em animal (CESAIRE, 1978, p.23).

Seria entăo esse o processo por que passa o personagem Luís Alex?

O devir-máquina de guerra e animal-fera do noivo emergem no território onde ele faz matilha, alia-se a outras hordas e legiôes no espaço onde qualquer ato de violência podia ser praticado contra os "selvagens desprovidos de humanidade" em nome do império, como atesta o filósofo Achille Mbembe:

O fato de que as colônias podem ser governadas na ausência absoluta de lei provém da negaçấo racial de qualquer vínculo comum entre conquistador e o nativo. Aos olhos do conquistador, 'vida selvagem' é apenas outra forma de "vida animal", uma experiência assustadora, algo radicalmente outro (alienígena). (MBEMBE, 2018, p.35)

A animalidade precisa ser entendida como a incapacidade dos bichos de agirem por meio da razáo, sendo a razáo característica apenas dos seres humanos. O homem é um animal racional e se diferencia dos demais seres por essa capacidade. Estaria o ser humano, portanto, dotado da capacidade de discernir entre o certo e o errado, entre o bem e o mal.

Luís Alex havia reprovado em Astronomia, Estatística e Probabilidade e confirma sua incapacidade para o raciocínio devido às circunstâncias da guerra.

“'Năo' - disse ele, cabisbaixo, com as măos imóveis. 'Tenho de te dizer uma coisa ter de fazer instruçấo e tropa, e guerra, e tudo isso, impede-me de pensar. Odeio tanto essa vida que năo consigo pensar'" (JORGE, 2004, p.152).

É possível traçar um perfil do personagem como uma espécie de Adolf Eichmann, o nazista responsável pelo envio de milhôes de judeus para morte nos campos de concentraçăo, personalidade analisada pela filósofa Hanna Arendt, enviada para fazer a cobertura do caso em Jerusalém, onde o acusado foi julgado depois de sequestrado na Argentina onde se escondia? Segundo Arendt, Eichmann năo era um monstro, psicopata, sujeito anormal que agia pelo simples prazer de praticar o mal. Tratava-se de um burocrata medíocre, cumpridor de ordens, às quais obedecia sem avaliar as consequências (morte de milhóes de pessoas); porém sabendo da importância que a obediência teria para sua carreira. Pensar nas consequências da deportaçâo para os campos de concentraçấo nâo fazia parte das atribuiçóes de Eichmann, preocupado demais em năo desagradar seus superiores. O que mais queria Luís Alex além de mostrar a Forza Leal, seu superior, sua capacidade de igualar-se a ele, de obedecer cegamente às suas ordens?

A comparaçăo parece absurda e de fato é, em certo ponto. Eichmann, diferente de Luís, era o burocrata que năo manchava as măos de sangue. Seus crimes de guerra foram praticados na assepsia de escritórios e assinatura de papéis. Os mortos do noivo mancharam sua farda de sangue. Ao ouvir Eichmann, Arendt destaca que sua incapacidade de falar estava diretamente afetada por sua falta de capacidade de pensar, no caso, pensar sob o ponto de vista do outro. $\mathrm{O}$ outro, em condiçōes de guerra é sempre um inimigo a ser aniquilado. $O$ judeu, no caso alemáo; o africano, no caso português. 0 noivo, tal qual o nazista, orgulha-se por conseguir cumprir seu papel como soldado em Moçambique, o que confirma o que Arendt observa no comportamento do alemáo: "Mas 
vangloriar-se é um vício comum, e uma falha mais específica, e também decisiva , no caráter de Eichmann era sua quase total incapacidade de olhar qualquer coisa do ponto de vista do outro" (ARENDT, 1999, p.60).

A lógica aplicada às colônias era a mesma dos campos de concentraçăo. Os negros moçambicanos estavam ali para serem mortos (houve um envenenamento em massa de negros por álcool metílico) pela instauraçăo de uma política do Estado português, ou seja, tratava-se de um assassinato estatal, para o qual a burguesia do Stella Maris fechava os olhos, como o fez parte das naçóes do mundo para o holocausto.

Para Paula Jordāo, o romance de Lídia Jorge é uma narrativa metaficcional que narra acontecimentos tidos como tabu para cultura portuguesa, como o assassinato de moçambicanos durante a guerra colonial e que questiona o romance como gênero totalizante e unificado. Evita é interpretada como contestadora da ordem dominante e ao mesmo tempo conivente com ela. Grande parte dos europeus sabia o que se passava nos campos de concentraçấo, assim como muitos portugueses tinham a dimensăo de que o que ocorria em Moçambique e Angola năo era apenas um movimento militar de manutençâo da ordem e dos territórios "pertencentes" a Portugal. Questionar o romance como gênero totalizante e unificado, segundo a pesquisadora, foi uma das tarefas da autora. A desta abordagem é questionar a totalizaçăo e unificaçăo do sujeito.

\section{CONSIDERAÇÕES FINAIS}

Identidade é um tema que vem sendo constantemente investigado por diferentes áreas de conhecimento: filosofia, história, sociologia, antropologia, crítica literária. Este artigo procurou abordar o tema sob a perspectiva filosófica e teórica da literatura. Por mais verossímil que seja o personagem objeto do estudo, procurou-se abordá-lo sem se esquecer de que se trata prioritariamente de uma figura ficcional. Os romances, no entanto, cumprem nâo apenas uma funçâo estética na sociedade, mas sâo capazes de provocar reflexóes acerca da realidade empírica dos sujeitos que os leem, por apresentar mimeticamente a realidade sem os filtros censores impostos muitas vezes pelos documentos oficiais e historiográficos.

Analisar os comportamentos do noivo para além de simples comportamentos, mas como devires identitários, é resultado da necessidade de pensar as identidades desvinculadas dos modelos que se pretendem totalizadores. Paradoxalmente, mesmo a ideia de sujeito fragmentado pressupóe uma visáo totalizadora. $\mathrm{O}$ que talvez perturbe na concepçấo deleuziana de devir é o abandono total das âncoras que sustentariam qualquer definiçâo fechada acerca dos sujeitos.

As condiçōes impostas pelas guerras exacerbam ainda mais as dificuldades de traço de um desenho pronto acerca de quem săo os indivíduos expostos a situaçóes onde as regras que separam o homem do mais selvagem dos bichos ou mítico das feras sâo abolidas. Nenhuma tentativa há, na presente argumentaçấo, de justificativa para as atrocidades praticadas por Luís Alex, ou qualquer soldado real em território africano. Mas, parafraseando Joâo Ubaldo Ribeiro no seu romance Diário do Farol (2002), o mal se propaga onde há terreno fértil. Haveria solo mais fértil do que uma guerra para qual eram enviadas pessoas para lutarem pela manutençăo, por meio da força, de algo que na realidade nunca fora realmente seu? 


\section{REFERÊNCIAS}

ARENDT, Hannah. Eichmann em Jerusalém: um relato sobre a banalidade do mal. Sáo Paulo: Companhia das Letras, 1999.

CANCLINI, Néstor Garcia. Culturas híbridas. Săo Paulo: Edusp, 2015.

CÉSAIRE, Aimé. Discurso sobre o colonialismo. Lisboa: Livraria Sá da Costa Editora, 1978.

DELEUZE e GUATTARI. Mil platôs: capitalismo e esquizofrenia. Vol. 1. Rio de Janeiro: Editora 34, 1995.

. Mil Platôs: capitalismo e esquizofrenia. Vol. 4. Săo Paulo: Editora 34, 1997.

JORDĀO, Paula. A costa dos murmúrios: uma ambiguidade inesperada. In: Lídia Jorge por outras palavras. Disponível em: https://archive.org/details/lidiajorgeinothe00jorg/page/n9. Acesso em: 22 out. 2018.

JORGE, Lídia. A costa dos murmúrios. Rio de Janeiro: Record, 2014.

HALL, Stuart. A identidade cultural na pós-modernidade. 11. ed. Rio de Janeiro: DP\&A, 2006.

MBEMBE, Achille. Crítica da razâo negra. Săo Paulo: N-1 Ediçōes, 2018.

. Necropolítica. Săo Paulo: N-1 Ediçōes, 2018.

SANTOS, Boaventura de Sousa. Pela māo de Alice: o social e o político na pós-modernidade. 14. ed. Săo Paulo: Cortez, 2013. 